\title{
ADVANCES IN ULTRA-PORTABLE FIELD FLUOROMETRY FOR DYE TRACING IN REMOTE KARST
}

\author{
Amaël Poulain \\ Department of Geology - University of Namur, Rue de Bruxelles nº1, Namur, B-5000, Belgium, \\ amael.poulain@unamur.be
}

Geert De Sadelaer

Royal Meteorological Institute of Belgium, Avenue Circulaire n³, Uccle, B-1180 Belgium, desa@oma.be

Gaëtan Rochez

Department of Geology - University of Namur, Rue de Bruxelles nº1, Namur, B-5000, Belgium, gaetan.rochez@unamur.be

Lorraine Dewaide

Department of Geology - University of Namur, Rue de Bruxelles nº1, Namur, B-5000, Belgium, lorraine.dewaide@unamur.be

\section{Vincent Hallet}

Department of Geology - University of Namur, Rue de Bruxelles nº1, Namur, B-5000, Belgium, vincent.hallet@unamur.be

\begin{abstract}
Dye tracing is a powerful tool in karst hydrogeology, allowing to specify groundwater connections, drainage organization and groundwater flow characteristics in impenetrable places (underground rivers, flooded caves...). The use of in situ monitoring devices enables improved investigation quality and efficiency during field work. Autonomous field fluorometers developed in the last decades now give reliable data for dye tracing with fluorescent tracers, with a limited investment on the field and limited human resources.
\end{abstract}

Nevertheless, the karst environment remains difficult to access and explore with scientific equipment. The size, weight, robustness and user-friendliness of the tool is determinant to improve the efficiency of field work and allow the acquisition of reliable data. In order to tackle this issue, we developed the Fluo-Green field fluorometer. This is a compact, extra-light and 2-in-1 field fluorometer (probe and data-logger) designed specifically for karst environment. The fluorometer allows the monitoring of fluorescein, turbidity, and water temperature with a user-defined resolution (1 minute to 1 day). An improved management of energy gives an extended lifetime that is useful for monitoring in remote locations. The compact device is especially useful to carry into the field and facilitates the monitoring of multiple sampling points.
Several dye traces in Belgian karst show the field performance of the Fluo-Green (precision, accuracy, resolution, lifetime...). Different karst environments were investigated using dye tracing: underground rivers, flooded caves, karst springs, vadose percolations. Those experiences illustrate the routine use of the Fluo-Green in various remote karst environments.

\section{Introduction}

Dye tracing by the mean of fluorescent dyes is widely used in hydrogeology and specifically in karst systems. This field methodology helps to refine groundwater connections, drainage organization and groundwater flow characteristics. The exploration of underground and impenetrable flow systems within karst networks can also benefit from this tool, in addition to scientific characterization of the karst media.

The measurement of dye concentration in groundwater can be performed with different methodologies. The most widely used techniques are the use of charcoal bags, manual or automatic water sampling and continuous monitoring using automatic field fluorometers. This last technique has many advantages such as the automatic measurement, a better temporal resolution, precision and accuracy, no sample transportation or analysis, no 
contamination of samples. Broadly speaking, it greatly improves hydrogeologic understanding, all the while saving time, human resources, and field efforts.

However, field work and scientific monitoring in karst environments are often difficult to implement. Access and progression in caves with scientific equipment may be challenging, especially in hydrologically active caves. For this reason, field equipment has to be compact and easy to use in variable cases of study, and replacement cost must not be prohibitive.

In order to deal with the challenge of cave dye tracing, this paper present results from the Fluo-Green field fluorometer (Poulain, 2017; Poulain et al., 2017), which is a compact and user-friendly fluorometer that is designed for cave use. The main characteristics of the device are shortly presented as well as two examples of comparative field results.

\section{Fluo-Green Characteristics}

The Fluo-Green fluorometer combines a fluorescenceturbidity-temperature probe and a data-logger in one small submersible equipment (Figure 1). A $470 \mathrm{~nm}$ channel is used to measure the fluorescein as it is the most used fluorescent dye in karst hydrogeology (Benischke et al., 2007). An additional $625 \mathrm{~nm}$ channel is used to measure water turbidity in order to evaluate possible interference with the fluorescence signal. The controller manages the measurement sequence with a user-defined time step between 1 minute and 1 day. Six AA batteries give a lifetime of 8000 to 9000 sequences ( 30 days for a 5 minutes time step). The data are stored on an internal $\mathrm{SD}$ card that can be read with a computer.

The routine laboratory calibration is made using 1 , 10 , and $100 \mathrm{ppb}$ solutions in a calibration bath and a computer. Standard resolution for fluorescein ranges between 0.06 and $0.09 \mathrm{ppb}$. The watertight casing is suitable for rivers, cave percolations and shallow karst pools. It has been successfully tested at -4 meter depth .

\section{Field Performances in Belgian Karst}

Field tests were performed to measure the performance of the fluorometer: lifetime, precision, accuracy, robustness. The main objective was to evaluate the ability of a simplified material to give reliable data that are consistent with the objectives and context of the trace (user expectations, financial resources...). Several

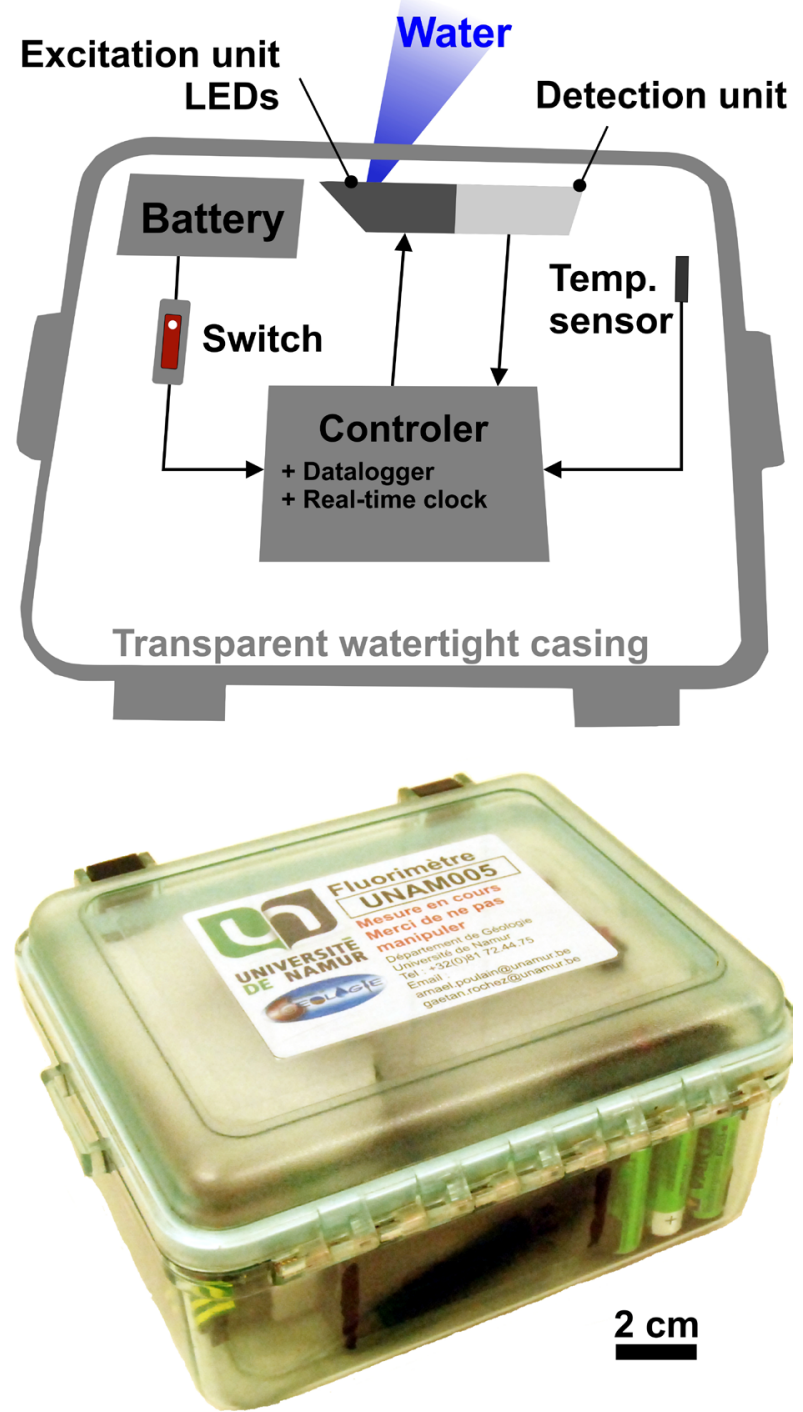

Figure 1. Schematic view and photograph of the Fluo-Green field fluorometer.

environments were tested, mainly in karst: underground rivers, springs, pools, and percolations. Two comparative traces are presented here: (1) the monitoring of a karst spring with Fluo-Green and automatic groundwater sampling, (2) the monitoring of a cave river with FluoGreen and a GGUN filter fluorometer.

Figure 2 shows the location of the two study sites in the south Belgium karst. They are two classical sinkhole to resurgence systems with discharge around 50 liters/ second at the sampling points.

The first dye trace was performed in order to compare the monitoring results between 3 Fluo-Green units and automatic groundwater sampling combined with 


\begin{tabular}{|l|l|}
\hline Properties & Value \\
\hline Size & $10 \times 16 \times 21 \mathrm{~cm}$ \\
\hline Weight & $2.75 \mathrm{~kg}$ \\
\hline Channels & $\begin{array}{l}470 \text { and } 625 \mathrm{~nm} \\
\text { Fluorescein and turbidity }\end{array}$ \\
\hline Turbidity range & $0.08-200 \mathrm{NTU}$ \\
\hline Time resolution & 1 minute -1 day \\
\hline Fluorescein resolution & $0.06-0.09 \mathrm{ppb}$ \\
\hline Saturation threshold & 3000 ppb (theoretical) \\
\hline Temperature resolution & $0.06^{\circ} \mathrm{C}$ \\
\hline Maximum depth & -4 meters \\
\hline Battery lifetime & $\begin{array}{l}8000 \text { measurements with } 6 \times A A \\
\text { batteries }\end{array}$ \\
\hline
\end{tabular}

Table 1. Fluo-Green characteristics.
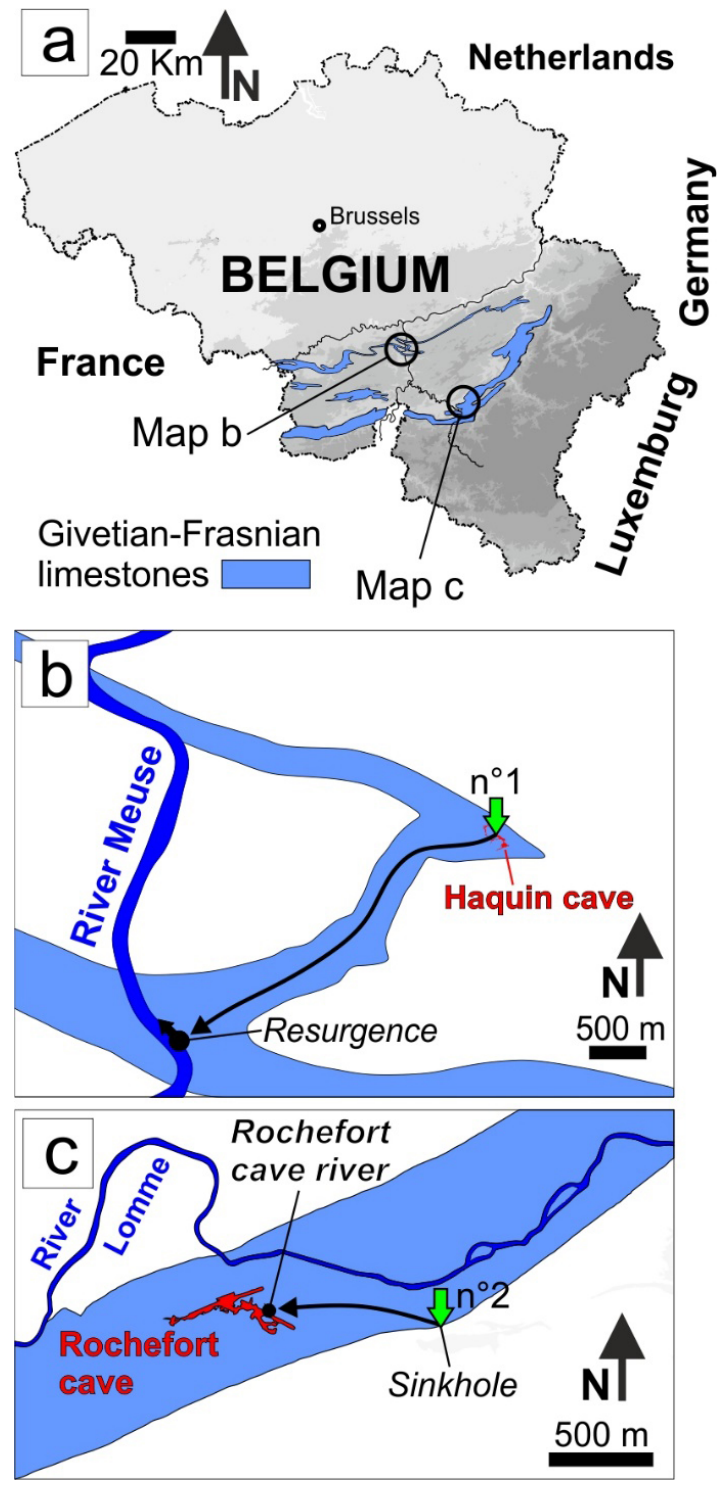

Figure 2. Location of the study sites in south Belgium karst. laboratory analysis (Figure 3). The lab analysis were made at the University of Namur using an Agilent spectrofluorometer. The Fluo-Green time resolution was 5 minutes and the water sampling resolution was 1 hour during 48 hours. The Figure 3 shows the breakthrough curve of this trace. The Fluo-Green breakthrough curves show the same results, there are also in good fit with spectrofluorometer analysis. The precision (3 synchronous measurement) and accuracy (comparison with spectrofluorometer) are very satisfying. Daylight noise is observable in the Fluo-Green results and can be corrected with differential measurement and additional smoothing of the data. A daylight cover should be implemented for such surface measurements.

The second dye trace shows the comparison between a Fluo-Green fluorometer and a GGUN FL30 fluorometer (Schnegg, 2002). The monitoring was performed in a cave river. Figure 4 shows the results with a strong similitude between the two breakthrough curves. The small difference may be attributed to the calibration procedures. This is a promising result because no additional filters are used on the Fluo-Green, which could be a potential issue for an accurate measurement of fluorescent dye. Dye tracing during stable conditions of turbidity and natural fluorescence may be performed in a reliable way using the Fluo-Green.

\section{Conclusions}

The objectives of this tool development were: (1) to provide a compact fluorometer that is useful to carry and

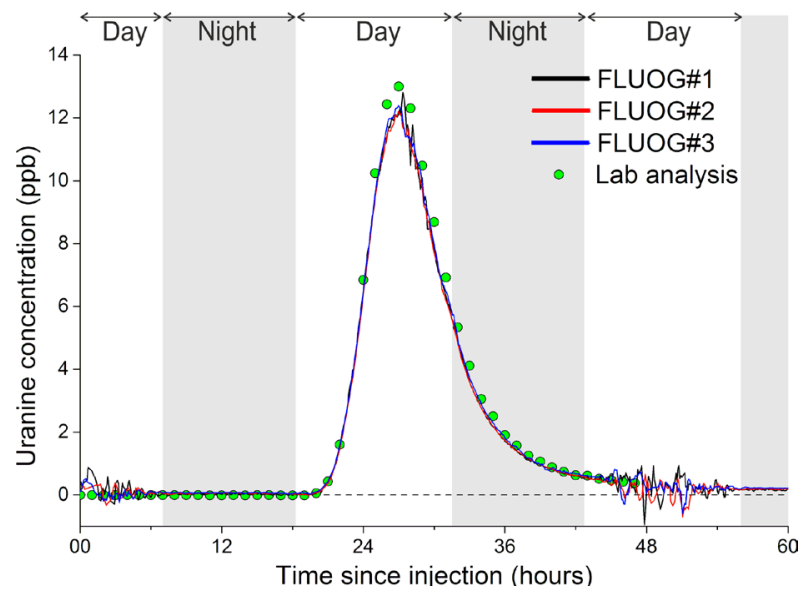

Figure 3. Breakthrough curves comparison between Fluo-Green and spectrofluorometer analysis in karst spring groundwater samples. 


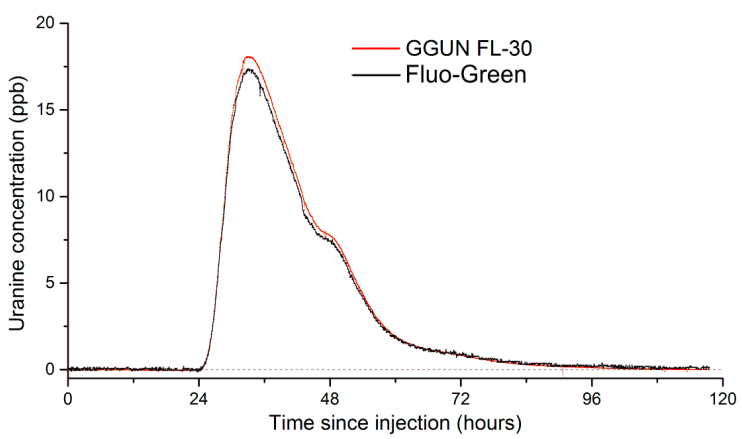

Figure 4. Breakthrough curve comparison between Fluo-Green and a GGUN FL30 filter fluorometer in the Rochefort cave river.

use even in the most challenging places (exploration, remote cave systems...), (2) simplify the material in order to limit the cost, size and user's handling and (3) ensure that the simplification affects in an acceptable way the precision, accuracy and field capabilities of the device. The tool should be adapted to the scientific issue and user's expectations. Thus, the Fluo-Green can be considered as an ultra-portable field fluorometer that is specifically suited for short-terms experiments, accessible for cavers and field researchers. So far, these objectives were reached but there is still a need for complementary experiences about field use, material durability and results in variable environments. Further improvements are expected has field results will bring new experience in the near future.

\section{References}

Benischke R, Goldscheider N, Smart C. 2007. Tracer techniques. In: Goldscheider N, Drew D, editors. Methods in karst hydrogeology. London (UK): Taylor \& Francis. p. 147-170.

Poulain A. 2017. Flow and transport characterization in vadose and phreatic zones of karst aquifers. $\mathrm{PhD}$ Thesis, University of Namur, Belgium, 226p.

Poulain A, Rochez G, Van Roy JP, Dewaide L, Hallet V, De Sadelaer G. 2017. A compact field fluorometer and its application to dye tracing in karst environments. Hydrogeology Journal 25: 1517-1524.

Schnegg PA. 2002. An inexpensive field fluorometer for hydrogeological tracer tests with three tracers and turbidity measurement. In: Bocanegra E, Martinez D, Massone H. editors. XXXII IAN and ALHSUD Congress Groundwater and Human Development. ISBN 987-557-063-9. 